\title{
The Case of the Overcooked Solder: Failure Analysis of AuSn Solder Die Attach using Optical and Electron Microscopy and EDS
}

\author{
T. J. Barbieri* and B. W. Condie** \\ *Arizona Product Analysis Lab, Freescale Semiconductor, Inc., 2100 E Elliot Rd, MD: EL315, \\ Tempe, AZ, 85284 \\ **Freescale Semiconductor, Inc., 2100 E Elliot Rd, MD: EL631, Tempe, AZ, 85284
}

An internal research team was conducting accelerated robustness experiments on a power CMOS design. The experimental die ( $<5$ mils thick) needed to be mounted in a carrier package for testing. For lack of a better option, the die were mounted on a $\mathrm{CuW}$ header in a ceramic-lidded package using Au-20wt $\% \mathrm{Sn}$ eutectic solder at a reflow temperature of $320^{\circ} \mathrm{C}$. The parts were baked for 16 hours at $200^{\circ} \mathrm{C}$, followed by functional testing, which all parts passed. The same procedure was repeated at $50^{\circ}$ increments until the parts failed (note that typical reliability tests occur at a maximum temperature between $150^{\circ} \mathrm{C}$ and $200^{\circ} \mathrm{C}$ ). Catastrophic failure occurred after baking for 16 hrs at $300^{\circ} \mathrm{C}$. Multiple fractures were observed in each die, along with metal blisters, and the die appeared to be folded upwards. The parts were submitted to the Failure Analysis (FA) lab in order to determine: a) the cause for failure, and b) to confirm if the source of the blistered surface metal was related to the large fields of aluminum metal used in the circuitry, indicating that the failures occurred during electrical testing.

A review of the binary phase diagram for the Au-Sn system revealed the root cause for failure. The melting temperature for eutectic AuSn solder is approximately $275^{\circ} \mathrm{C}$ [1]. Historically, reflow temperatures for conventional $\mathrm{PbSn}$ solders have typically been $15-20^{\circ}$ above the melting temperature, but reflow time has been limited to under a few minutes because of the rapid dissolution of surface metals by the liquid solder [2,3]. By taking these parts with AuSn die-attach to $300^{\circ} \mathrm{C}$ and making the mistake of holding them there for $16 \mathrm{hrs}$, the AuSn solder was given extensive time to melt, reflow, and interact greatly with the surrounding materials. The positive aspect of this conclusion was that failure was not related to the die, but due to an incorrect choice of test bed combined with excessive test parameters.

The unusual appearance of the failed parts deserved further investigation, and the subsequent analysis makes for an excellent case-study showcasing the variety of microscopic and microanalytical tools used in today's microelectronic failure analysis laboratory. Optical light microscopy was employed during the initial evaluation, during which reflowed and solidified metal was observed running between delaminated layers of interlayer dielectric (ILD) below the die surface and even bursting through the surface at some points. Scanning electronic microscopy was utilized to more extensively characterize the physical appearance of the damage. SEI imaging provided structural information: some die edges were raised a full millimeter above the header surface, holes were observed in the sides of die with traces of solidified metal dripping out of them, and the backside of the die showed signs of signs of chemical consumption. BSE imaging provided invaluable compositional information by highlighting the fact that all of the reflowed metal was a heavy metal and that the reflowed AuSn contained large amounts of a low-atomic number material. These sites identified with BSE imaging were chemically characterized using Energy Dispersive 
Spectroscopy. EDS analysis of the surface confirmed that all of the reflowed metal responsible for the damage came from the AuSn die-attach, and excess AuSn located away from the die contained large amounts of Si. A cross-section was prepared through one of the AuSn eruption sites. Through the use of SEM imaging and EDS mapping of this cross-section, a series of events that had generated the violent chemical-mechanical damage was formulated.

[1] H. Baker (ed), ASM Handbook, Vol. 3: Alloy Phase Diagrams, ASM International, Materials Park, 1992.

[2] N. Armendariz and P. Paulraj, 30 ${ }^{\text {th }}$ ISTFA Proceedings, (2004) 103.

[3] C.E. Ho et al., IEEE Trans. Comp., Packag., Manf. Tech., v20, \#3, (July 1997) 188.
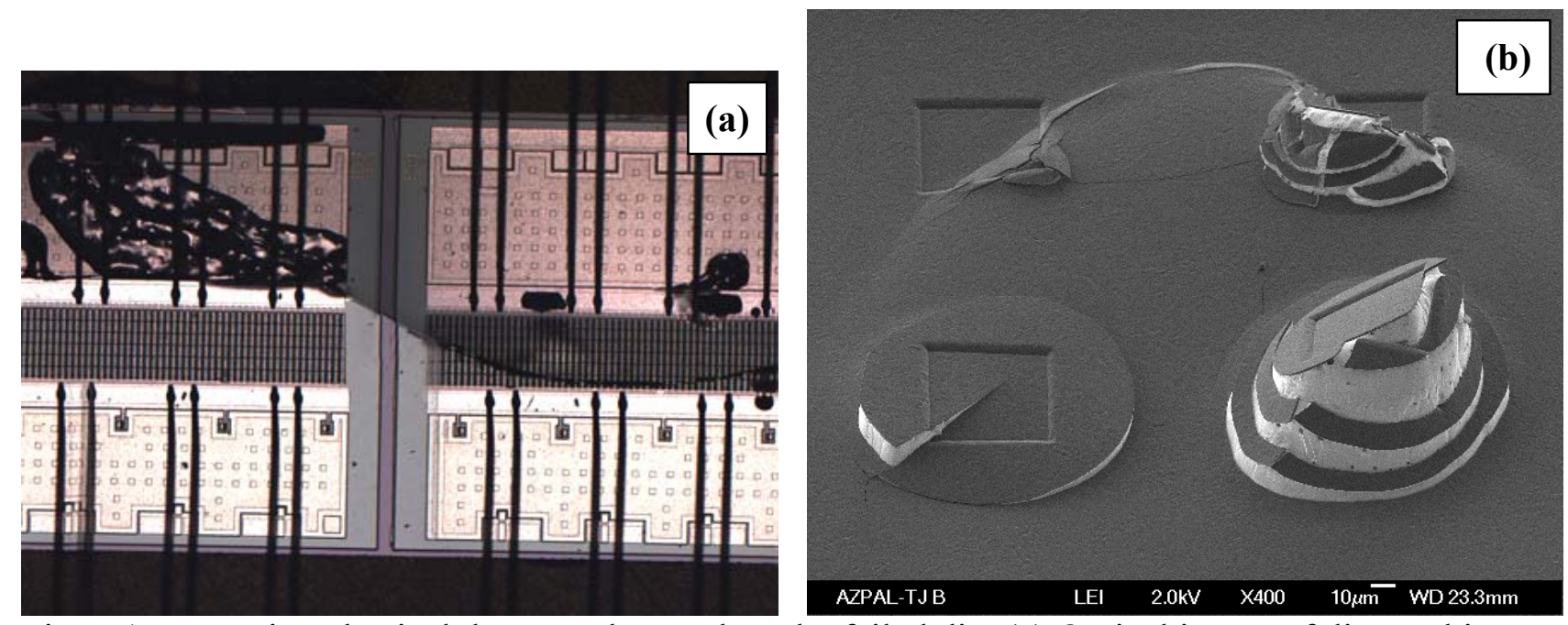

Figure1: Excessive physical damage observed on the failed die: (a) Optical image of die cracking and metal blistering, (b) SEI image of AuSn eruptions.
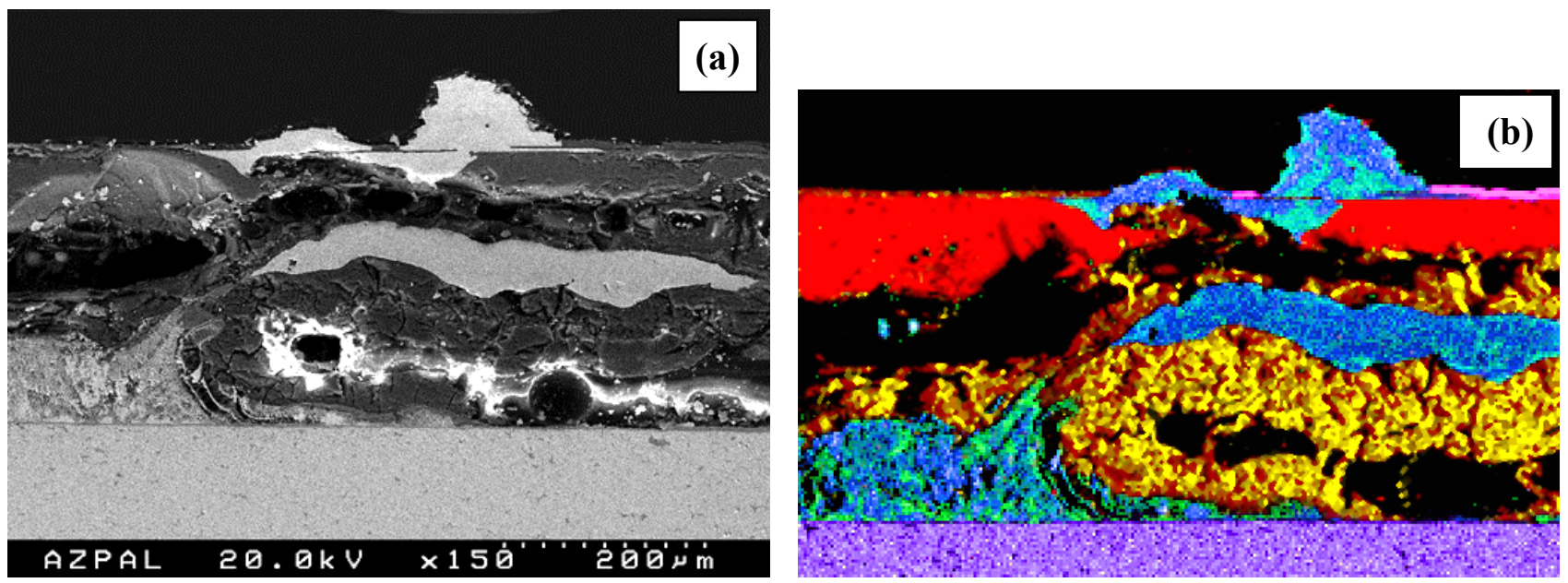

Figure 2: Analysis of an AuSn cross-section: SEI image of the cross-section, (b) EDS map of the cross-section (blue $=\mathrm{Au}$, green $=\mathrm{Sn}, \mathrm{red}=\mathrm{Si}$, yellow $=\mathrm{O}$, purple $=\mathrm{W}$, pink $=\mathrm{Al}$ ). Note the varying, chewed appearance of the $\mathrm{Si}$ die, the large field of $\mathrm{SiO}_{2}$, and the 3 islands of $\mathrm{AuSn}$ : one adjacent to the substrate, one embedded in the $\mathrm{SiO}_{2}$ field, and one bursting through the top of the $\mathrm{Si}$ die. 